Montenegro, Mozambique, Poland, Serbia, Slovakia, Slovenia, Thailand (suspended 2014), Ukraine, United Arab Emirates, Uruguay.

Headquarters: 19-21 avenue Bosquet, 75007 Paris, France. Website (limited English): http://www.francophonie.org Secretary-General: Michaëlle Jean (Haiti).

\section{International Organization for Migration (IOM)}

Established in 1951, the International Organization for Migration (IOM) is the principal intergovernmental organization in the field of migration.

Members (162 as of Feb. 2016). Afghanistan, Albania, Algeria, Angola, Antigua and Barbuda, Argentina, Armenia, Australia, Austria, Azerbaijan, Bahamas, Bangladesh, Belarus, Belgium, Belize, Benin, Bolivia, Bosnia and Herzegovina, Botswana, Brazil, Bulgaria, Burkina Faso, Burundi, Cabo Verde, Cambodia, Cameroon, Canada, Central African Republic, Chad, Chile, Colombia, Comoros, Democratic Republic of the Congo, Republic of the Congo, Costa Rica, Côte d'Ivoire, Croatia, Cyprus, Czech Republic, Denmark, Djibouti, Dominican Republic, Ecuador, Egypt, El Salvador, Eritrea, Estonia, Ethiopia, Fiji, Finland, France, Gabon, Gambia, Georgia, Germany, Ghana, Greece, Guatemala, Guinea, Guinea-Bissau, Guyana, Haiti, Holy See, Honduras, Hungary, Iceland, India, Iran, Ireland, Israel, Italy, Jamaica, Japan, Jordan, Kazakhstan, Kenya, Kiribati, South Korea, Kyrgyzstan, Latvia, Lesotho, Liberia, Libya, Lithuania, Luxembourg, Macedonia, Madagascar, Malawii, Maldives, Mali, Malta, Marshall Islands, Mauritania, Mauritius, Mexico, Micronesia, Moldova, Mongolia, Montenegro, Morocco, Mozambique, Myanmar, Namibia, Nauru, Nepal, Netherlands, New Zealand, Nicaragua, Niger, Nigeria, Norway, Pakistan, Panama, Papua New Guinea, Paraguay, Peru, Philippines, Poland, Portugal, Romania, Rwanda, St Kitts and Nevis, St Lucia, St Vincent and the Grenadines, Samoa, São Tomé e Príncipe, Senegal, Serbia, Seychelles, Sierra Leone, Slovakia, Slovenia, Somalia, South Africa, South Sudan, Spain, Sri Lanka, Sudan, Suriname, Swaziland, Sweden, Switzerland, Tajikistan, United Republic of Tanzania, Thailand, Timor-Leste, Togo, Trinidad and Tobago, Tunisia, Turkey, Turkmenistan, Uganda, Ukraine, UK, USA, Uruguay, Vanuatu, Venezuela, Vietnam, Yemen, Zambia and Zimbabwe. A further nine countries have observer status.

Activities. IOM works to help ensure the orderly and humane management of migration, to promote international co-operation on migration issues, to assist in the search for practical solutions to migration problems and to provide humanitarian assistance to migrants in need, be they refugees, displaced persons or other uprooted people. The IOM Constitution gives explicit recognition to the link between migration and economic, social and cultural development, as well as to the right of freedom of movement of persons. IOM's programme budget for 2012 exceeded US\$1.2bn., funding over 2,300 active programmes and more than 7,800 staff members serving in over 470 field offices in more than 100 countries.

Official languages: English, French and Spanish.

Headquarters: Route des Morillons 17, POB 71,

CH-1211 Geneva 19, Switzerland.

Website: http://www.iom.int

Director-General: William Lacy Swing (USA).

\section{International Organization for Standardization (ISO)}

Established in 1947, the International Organization for Standardization is a non-governmental federation of national standards bodies from 161 countries worldwide, one from each country. ISO's work results in international agreements which are published as International Standards. The first ISO standard was published in 1951 with the title 'Standard reference temperature for industrial length measurement'.

Some 19,500 ISO International Standards are available on subjects in such diverse fields as information technology, textiles, packaging, distribution of goods, energy production and utilization, building, banking and financial services. ISO standardization activities include the widely recognized ISO 9000 family of quality management system and standards and the ISO 14000 series of environmental management system standards. Standardization programmes are now being developed in completely new fields, such as food safety, security, social responsibility and the service sector.

Mission. To promote the development of standardization and related activities in the world with a view to facilitating the international exchange of goods and services, and to developing co-operation in the spheres of intellectual, scientific, technological and economic activity.

Headquarters: 8 Chemin de Blandonnet, CP 401,

$\mathrm{CH}-1214$ Vernier, Geneva, Switzerland.

Website: http://www.iso.org

Secretary-General (acting): Kevin McKinley (Canada).

\section{International Road Federation (IRF)}

The IRF is a non-profit, non-political service organization whose purpose is to encourage better road and transportation systems worldwide and to help apply technology and management practices to give maximum economic and social returns from national road investments.

Founded following the Second World War, over the years the IRF has led major global road infrastructure developments, including achieving $1,000 \mathrm{~km}$ of new roads in Mexico in the 1950s, and promoting the Pan-American Highway linking North and South America. The IRF works together with members and associates in 118 countries, promoting social and economic benefits that flow from well planned and environmentally sound road transport networks. It publishes World Road Statistics, covering over 200 countries and territories.

Headquarters: Madison Place, 500 Montgomery St., Fifth Floor, Alexandria, Virginia 22314, USA.

Website: http://irfnews.org

Chairman: Abdullah A. Al-Mogbel (Saudi Arabia).

\section{International Seabed Authority (ISA)}

The ISA is an autonomous international organization established under the UN Convention on the Law of the Sea (UNCLOS) of 1982 and the 1994 Agreement relating to the implementation of Part XI of the UNCLOS. It came into existence on 16 Nov. 1994 and became fully operational in June 1996. 